\title{
Problems and Countermeasures of Activity-based Costing in Practice
}

\author{
Fanfan Sun \\ School of Economics and Management, Nanjing University of Science and Technology, Nanjing \\ 210000, China \\ 1153462936@qq.com
}

Keywords: Activity-based costing; management decision; environment; cost benefit

\begin{abstract}
In recent years, with the continuous deepening of China's market economy and the continuous development of economic globalization, the domestic and international market competition has become increasingly fierce. Faced with the increasingly competitive economic market, how to better improve their core competitiveness has become an urgent problem for most domestic enterprises. Cost management runs through the entire process of enterprise management and plays an extremely important role in reducing enterprise cost. As a new type of cost management method, the activity-based costing method has a greater impact on reducing business operations expenditures and optimizing business operations and management activities. However, because the activity-based costing method has encountered various factors in the application process, it has not been popularized in Chinese enterprises. On this basis, this paper focuses on the problems and corresponding countermeasures in the practical application of the activity-based costing method.
\end{abstract}

\section{Introduction}

\subsection{Background}

In recent years, with the continuous deepening of China's market economy and the continuous development of economic globalization, the domestic and international market competition has become increasingly fierce. Cost management runs through the entire process of enterprise management and plays an extremely important role in reducing enterprise cost. The following is an environmental background analysis of the application of the activity-based costing method through the PEST analysis method.

P-Politics, in the past 30 years of reform and opening up, the living environment of Chinese enterprises has been constantly changing with the national conditions. The management systems and models of foreign enterprises have had a profound impact on Chinese enterprises. Besides, due to the freedom under the open economy Competition, enterprises are facing increasingly fierce survival challenges, the market's survival of the fittest makes companies must do their utmost to maintain their core competitiveness.

E-Economic, in recent years, due to the development of technologies such as the Internet, the 
capital market is currently in an excessively active state, which has caused the Chinese economy from entity to virtual, so traditional manufacturing has been hit in different degrees.

S-Society, the policy of opening the country is not only to integrate the domestic economic technology with the world, but also to absorb the essence and remove the dross in the social and cultural aspects. The various concepts of the people have also quietly changed, everyone's interest in emerging things and their ability to accept learning has improved greatly in the open social and cultural environment.

T-Technology, due to the advancement of technology, the achievements made by Chinese enterprises in mechanized production and operation are obvious. Now more and more advanced automatic machines and equipment are running around the clock in the workshop. Accountants should think about how the cost of the machine is reasonably distributed and its importance of business decision-making.

\subsection{Research significance}

Theoretical significance: Activity-based costing is an important component of management cost accounting. The study of the activity-based costing method can test theory and correct perfect theory.

Practical significance: Activity-based costing is an important cost calculation method superior to traditional costing methods. Studying the problem status of the operating cost method in practical application helps enterprises to use the activity-based costing method flexibly based on their own characteristics, which will maximize the benefits of activity-based costing method and help managers make sound decisions.

\subsection{Literature review}

The activity-based costing method has a long history, and because of its theoretical and practical significance, there is no shortage of scholars to study it. Yaping Ning (2012) obtained three factors which will effect the application of the activity-based costing method after the empirical case study: indirect cost importance, market competitiveness and product differentiation; Bin Lin et al. (2014) pointed out through case study analysis that the successful implementation of the activity-based costing method relies on the attention of leaders and positive participation of all employees[1]; Weice Shi, Fajie Wei (2015) explained the application conditions of activity-based costing based on the cost function expression based on activity-based costing.

\section{Overview of Activity-Based Costing Theory}

\subsection{The background and reasons for the activity-based costing}

The activity-based costing method was born in the United States. As early as 1941, the American accountant Professor Kohler first proposed the concepts of assignment and operation account setting in the Accounting Forum. In the 1980s, Cooper and Kaplan made a more in-depth study of the activity-based costing method from the practical significance of the activity-based costing method and the choice of cost drivers. This is a milestone in the maturity and improvement of the activity-based costing method [2]. At the end of the 20th century, production automation and intelligence were increasing, more and more enterprises began to transform from labor-intensive to capital-intensive and technology-intensive, so direct labor costs were generally reduced, and indirect costs were relatively increased, which broken the assumption of "direct costs are high" in the traditional cost method. As we all know, the traditional cost method allocates overhead 
according to manual working hours and workload, which seriously distort the cost and is not conducive to enterprise managers made decisions through financial data. Therefore, the activity-based costing method has emerged in such social developments.

\subsection{The advantages of activity-based costing over traditional costing}

Compared with the traditional cost method, the activity-based costing method has the following advantages:

\subsubsection{Get more accurate product and product line costs}

The activity-based costing method uses the activity as the calculation center. According to the resource driver, the actual consumption of resources is distributed to each activity center, and according to the activity motivation, the expenses collected in the activity center are allocated to each product, so that the actual product cost of various products can be calculated, thus collecting accurate product costs.

\subsubsection{Helps improve cost control}

The traditional cost method simply carries out the accounting after the daily activities of the enterprise, and the activity-based costing method requires the manager to think about the cost "from the beginning to the end", and the so-called beginning and ending is to think and analyze the necessity of cost from the given price[3], so as to consider the rationality of product cost structure while accounting cost, the way of activity as the cost calculation center can help managers identify the process that has no effect on product value in the production process, so that it can help the enterprise achieve cost control improvements.

\subsubsection{Provide information support for strategic management}

We know that cost as an important accounting factor in financial statements is a key point that every enterprise can't ignore. The cost and the accuracy of accounting directly affect the profit level of the company. Accurate and reasonable cost data can provide decision makers correct information support and help decision makers make optimal decisions.

\section{The resistance of activity-based costing in practice}

The above-mentioned extensive coverage analyzes the advantages of the activity-based costing method over the traditional costing method. However, due to the limitations of the environment, applicable conditions, etc., Chinese enterprises have encountered many obstacles in applying the activity-based costing method. The following mainly explains the factors that restrict the implementation of the activity-based costing method from several aspects.

\subsection{Environmental issue}

First of all, from the perspective of the external environment, China is currently dominated by small and medium-sized enterprises. The analysis of the market research and investment strategy of Chinese enterprises in 2017-2022 shows that there are 40 million SMEs in China, accounting for $99 \%$ of the total number of enterprises. We know that SMEs are far behind large enterprises in terms of capital scale and hardware and software facilities. They cannot get sufficient support from funds and corresponding facilities. Therefore, considering the factors of enterprises and cost-effectiveness, many small and medium-sized enterprises will choose traditional costing 
method.

In the internal environment, the perfection degree of sharing information equipment in enterprises also has an impact on it. ERP is an indispensable medium in the implementation of activity-based costing. The application in China is not so optimistic. Nowadays, many enterprises have begun to quote ERP systems, but due to scale and financial strength, ERP does not really play its full benefits in most enterprises. Beyond that, most of which are at the primary level, and the successfully application exists in the large enterprises.

\subsection{Technical problem}

The accounting procedure of activity-based costing is much more difficult than the traditional costing method. First of all, in the classification and collection of the activity cost database, the relevant business personnel need to know the company's production and operation on the basis of proficient cost accounting, and the situation of each company is different, so the standards for the classification of the activity cost center are different; in addition, the choice of cost drivers is also a major problem in the cost accounting process; finally, the relevant cost drivers are calculated. Distribution rate, the workload of various products also requires the internal control situation of enterprises and the degree of internal information sharing at a high level.

\subsection{Personnel quality problem}

The overall quality level of accountants is another factor that affects the implementation of the ABC. First of all, at the educational level, most of the accounting personnel in China currently only have secondary school or junior college education, and according to the characteristics of the training program of the college, the main training objective is to be able to carry out basic accounting talents for simple accounting, without strong management accounting theoretical basis[4]; secondly, in the knowledge structure, the accounting industry as a professional industry, so most accountants are only proficient in the theory and practice of accounting, not familiar with the management of other areas of the enterprise.

\subsection{Problems with the activity-based costing process itself}

Everything has two sides, although the activity-based costing method has many advantages over the traditional costing method, it also has certain limitations. First of all, because the activity-based costing method can't avoid a certain degree of subjective factors, each accountant will have different considerations in selecting the cost driver and confirming the homogeneous cost library, so that the enterprise will have a larger difference between calculated cost and actual cost[5]. Secondly, there is a certain discrepancy between the activity-based costing method and the current accounting standards of the enterprise. The activity-based costing method is based on the management accounting theory, while the traditional costing law is the scope of the current accounting system.

\section{Countermeasures for Solving the Problem of Activity-Based Costing in Practice}

\subsection{Establish an internal environment that contributes to the implementation of $\mathrm{ABC}$}

Comprehensive, timely and accurate financial information is a sufficient condition for the successful implementation of the ABC. In manufacturing enterprises, products are accompanied by a huge flow of information in the process of production to sales, so only accurate and timely collection and acquisition of these information can ensure high cost accounting accuracy. At this 
time, the perfect information system is an important weapon for the promotion of enterprise activity-based costing. Enterprises should pay full attention to the construction of information systems. First, they should fully launch the ERP system and mature applications. Secondly, the operation cost accounting software will be developed to make the ABC implementation in a higher standard.

\subsection{Combine the principle of cost-effectiveness, gradually promote from point to point}

When SMEs are faced with the cost-effectiveness of the ABC, they should pay attention to the cost-benefit principle. In the $\mathrm{ABC}$, the general principle to be followed is that if the cost of selecting a certain cost is much greater than the resulting benefit, it is possible to consider replacing another cost driver. For example, when an indirect cost is relatively small and its importance level is not high, the calculation of the cost driver can be simplified.

The activity-based costing method is more applicable to companies with a well-developed management information system, a high degree of automation, and a large proportion of indirect costs. Among Chinese enterprises, large and medium-sized state-owned enterprises generally have a relatively complete accounting management information system and a high level of automated production[6]. Therefore, it is possible to consider piloting large and medium-sized state-owned enterprises, summing up practical experience and continuously optimizing enterprise implementation operations, then promoted the cost method in other companies.

\subsection{Do a good job in strategic support, strengthen departmental coordination, and establish a scientific management system}

When implementing the activity-based costing method, enterprises should incorporate them into the scope of enterprise strategic management and coordinate the various systems of business management to form a system project that can fully meet the objectives of enterprise management. In addition to the support of a more complete management information system in the enterprise, coordination of various departments is also essential, and the scientific management system and production organization are also indispensable in the successful implementation of the activity-based costing method. First of all, it is important to set up a reasonable accounting institution in the finance department, formulate a scientific post responsibility system, and ensure that each post can be supervised and controlled by each other. Secondly, an effective internal and external supervision mechanism should be set up, and all department should have a good internal control system, so that the entire enterprise can operate efficiently under the perfect scientific management system, laying a good foundation for the successful implementation of the activity-based costing method.

\subsection{Improve the quality of employees}

Accountants are an important part of the cost accounting process, so enterprises should vigorously improve the professional level of accounting personnel through training and other means. According to the universality of the current situation in China, it is possible to conduct pilot training in some enterprises first, focus on strengthening the professional level of cost accounting in theory and practice, and record the results of the training process and so on. Communicate and summarize the best training methods so that they can be promoted to more companies when the time is right. In the long-term talent training, first of all, in the student training objectives of accounting-related majors, it is necessary to pay more attention to activity-based costing method to form a preliminary activity management cognition system. Secondly, in the training of the accountants who have been 
employed, the enterprise must strengthen the cultivation of compound professionals.

\subsection{Flexible use in conjunction with the specific conditions of the company itself}

In the method of reducing subjectivity, enterprises can choose to improve the overall professional level of accountants through some means; secondly, in terms of certain discrepancies between the activity-based costing method and the current accounting standards, it can be considered that activity-based costing method is implemented in the internal management of the enterprise, and the traditional cost method is still adopted for external disclosure. Although this is a more costly and manpower way, the cost-effectiveness of the advanced management concepts included in the activity-based costing method, coupled with the gradual development of enterprise management information systems and normalized of the internal system, the benefit of the activity-based costing method will become more and more obvious.

\section{Conclusion}

Although the activity-based costing method is relatively late in China and its development is slow, it is an important part of management accounting and has advanced management ideas, and the development prospects in China are bound to be very broad and unstoppable. In the practical application of Chinese enterprises, they should complement and integrate with the traditional cost method, combine the current environment of the enterprise, make full use of the existing resources of the enterprise, and use the activity-based cost method as low-cost as possible, so that driving application and promotion of activity-based costing in China.

\section{References}

[1] Dongsheng Chen, 2012. The Difficulties and Countermeasures of the Activity-based Costing in China. Accountant. [2] Zhengjie Wu, 2013. Summary and Prospect of Applied Research on Activity-Based Costing in China. Friends of Accounting.

[3] Xiangfei Yuan, 2014. Thoughts on the Application of Activity-Based Costing in Practice. Contemporary Accounting. [4] Longjie Li, 2015. Analysis on the Improvement of the Activity-Based Costing Method under the New Situation of Management Accounting. Research of Finance and Accounting.

[5] Lei Pang, 2016. Analysis on the Application and Implementation Countermeasures of Activity-Based Costing Method in Enterprises. China Chief Financial Officer.

[6] Yuanbin Bao, 2016. Cost-benefit analysis of ABC application. Times Finance.

[7] Liqiong Zhao, Chang Ren, 2016. Application Design of Activity-Based Costing in Precision Casting Enterprises_-Taking SX Company as an Example. Friends of Accounting.

[8] Limeng Zhao, Rong Fu, Ming Zhou, 2017. A Summary of the Development and Application Research of Activity-Based Costing Theory. China Economic \& Trade Herald.

[9] Liqin Jiang, Mingyue Xu, Yanli Qiao, 2017. Application of Activity-Based Costing in Enterprise Product Cost Management. Finance and Accounting Monthly.

[10] Qinglei Wang, 2017. Activity-based costing and its application in the new situation. Marketing Management Garden. 